\title{
Kinetics and regulation of fructose and glucose transport systems are responsible for fructophily in Zygosaccharomyces bailii
}

\author{
Susana Sousa-Dias, ${ }^{1}$ Teresa Gonçalves, ${ }^{1}$ Javier S. Leyva, ${ }^{2}$ José M. Peinado \\ and Maria C. Loureiro-Dias ${ }^{1}$
}

1 Laboratory of

Microbiology, Gulbenkian

Institute of Science, Ap. 14,

2781 Oeiras Codex

Portugal

2 Department of Microbiology, Faculty of Biology, Complutense

University, E-28040

Madrid, Spain

\author{
Author for correspondence: Maria C. Loureiro-Dias. Tel: +351 14431344. Fax: + 35114431631. \\ e-mail:mcdias@gulbenkian.pt
}

\begin{abstract}
A strain of Zygosaccharomyces bailii was selected for studies on fructose and glucose transport to determine the basis of the fructophilic behaviour of this species. Fructose was transported by a specific low-affinity, high-capacity transport system with a $K_{\mathrm{m}}$ of $65.6 \mathrm{mM}$ and a $V_{\max }$ of $6.7 \mathrm{mmol} \mathrm{g}^{-1} \mathrm{~h}^{-1}$ for cells grown on $2 \%(w / v)$ fructose, while the transport of glucose showed a $K_{m}$ of $7 \mathrm{mM}$ and a $V_{\max }$ of $1.7 \mathrm{mmol} \mathrm{g}^{-1} \mathrm{~h}^{-1}$ for cells grown on $2 \%(w / v)$ glucose. The transporter of glucose also accepted fructose as a substrate. Fructose inactivated the glucose transporter; inactivation was faster at higher concentrations. Both transporters were partially inductive. Measurements of metabolic fluxes and respiration and fermentation rates supported the general features identified by transport measurements. The kinetics and regulation of transport of the two sugars confirm the fructophilic behaviour previously described by other authors.
\end{abstract}

Keywords: Zygosaccharomyces bailii, yeast, fructophily, fructose transport, glucose transport

\section{INTRODUCTION}

While most yeasts ferment glucose preferentially to other sugars, it has been shown that Zygosaccharomyces bailit exhibits the opposite behaviour: when glucose and fructose are both available in the medium, fructose is utilized more rapidly.

The transport of glucose and fructose has been characterized in several yeast species and, in Saccharomyces cerevisiae, it has been shown that these sugars share the same carrier(s) (Cirillo, 1968; Heredia et al., 1968). Transport is by a facilitated diffusion mechanism, the affinity depending on the physiological state of the cells (Walsh et al., 1994). The data that have been reported indicate that the affinity for glucose is five (Cirillo, 1968) or ten (Kotyk, 1967) times higher than for fructose. This difference would support the early recognized preference of $S$. cerevisiae for glucose, particularly in the case of the typical wine yeasts (Bourquelot, 1886). In Saccharomyces bayanus and Saccharomyces pastorianus, although fructose also utilizes the carrier(s) for glucose, a specific highaffinity, low-capacity fructose- $\mathrm{H}^{+}$symport has been described (Rodrigues de Sousa et al., 1990) which does not

This work is dedicated to the memory of Professor Nicolau van Uden. accept glucose as a substrate. Nevertheless, there is no indication that fructose is consumed at significantly higher rates by these species when glucose is present.

The basis of the phenomenon of fructophily in yeasts was first investigated by Sols (1956), who showed that the phosphorylation of the sugars was not involved, suggesting a role for 'transferring agents prior to phosphorylation'. Emmerich \& Radler (1983) presented evidence indicating that the step of transport would be certainly involved in the so-called fructophily. However, in their studies, transport was not separated from metabolism, since rather long periods of incorporation of the substrates were considered. If the data previously presented are in fact a consequence of the mechanisms and regulation of the transport systems for fructose and glucose, we are dealing with a situation which is new in yeasts. The purpose of the present work was to characterize these transporters on a kinetic basis and to understand their regulation, by the measurement of initial uptake rates of fructose and glucose, over short periods.

\section{METHODS}

Micro-organisms and culture conditions. The strain of Zygosaccharomyces bailii (ISA 1307) used in this work was isolated from a sparkling-wine production plant and was selected for the 
unusual ability to grow in the presence of 800 p.p.m. potassium sorbate (Neves et al., 1994). The cultures were kept on YPD slants (yeast extract, $10 \mathrm{~g} \mathrm{l}^{-1}$; peptone, $20 \mathrm{~g} \mathrm{l}^{-1}$; glucose, $20 \mathrm{~g} \mathrm{l}^{-1}$; agar, $18 \mathrm{~g} \mathrm{l}^{-1}$ ). Twenty-four-hour-old cultures were used as inocula. The cells were grown in $500 \mathrm{ml}$ flasks with $200 \mathrm{ml}$ mineral medium (van Uden, 1967), usually containing, unless otherwise stated, $2 \%(\mathrm{w} / \mathrm{v})$ glucose, fructose or glycerol, on an orbital shaker at $30^{\circ} \mathrm{C}$. Growth was monitored by measuring the $\mathrm{OD}_{640}$ (using a Spectronic 20, Milton Roy) for determination of maximum specific growth rates $\left(\mu_{\max }\right)$. Yield coefficients $(Y)$ were based on dry weight determinations and consumption of glucose and fructose was monitored by standard enzymic methods (kits from Boehringer). Specific consumption rates of fructose and glucose were calculated as the ratio $\mu_{\max } / Y$. At an $\mathrm{OD}_{640}$ of 0.8 (mid-exponential phase), the cells were harvested by centrifugation at 10000 r.p.m. in an IEC B-20 centrifuge, washed twice with distilled water at $4{ }^{\circ} \mathrm{C}$ and resuspended in water to a final concentration of about $50 \mathrm{mg}$ dry weight $\mathrm{ml}^{-1}$. These cells were kept on ice for up to $30 \mathrm{~min}$ for transport assays.

Initial uptake measurements. The cell suspension $(20 \mu \mathrm{l})$ was mixed with $100 \mathrm{mM}$ Tris/citrate buffer $(\mathrm{pH} 5.0 ; 20 \mu \mathrm{l})$ in $10 \mathrm{ml}$ conical centrifuge tubes. After $2 \mathrm{~min}$ incubation at $26^{\circ} \mathrm{C}$ in a water-bath, uptake was initiated by the addition of $\mathrm{D}$-[U$\left.{ }^{14} \mathrm{C}\right]$ fructose $\left[290 \mathrm{mCi} \mathrm{mmol}^{-1} \quad\left(10.73 \mathrm{GBq} \mathrm{mmol}^{-1}\right)\right]$ or $\mathrm{D}-\left[\mathrm{U}^{-14} \mathrm{C}\right]$ glucose $\left[283 \mathrm{mCi} \mathrm{mmol}^{-1}\left(10.47 \mathrm{GBq} \mathrm{mmol}^{-1}\right)\right]$ at appropriate concentrations; after $5 \mathrm{~s}$ the incorporation was stopped by the addition of $5 \mathrm{ml}$ cold distilled water. Cells were filtered through wet glass-fibre filters (Whatman $\mathrm{CF} / \mathrm{C}$ ) at reduced pressure and washed with $10 \mathrm{ml}$ cold distilled water. All determinations were performed in triplicate. For blanks, $5 \mathrm{ml}$ cold distilled water was added prior to the addition of the labelled sugars. These were subtracted from the readings. In a set of parallel experiments, $500 \mathrm{mM}$ glucose was used instead of water for stopping the incorporation and washing, as described by Walsh et al. (1994) for preventing nonspecific binding. In this case, values were slightly lower, but the difference was below $5 \%$. When testing uranyl ions as inhibitors, $200 \mathrm{mM}$ MES ( $\mathrm{pH}$ 5) was added as a buffer, since citrate chelates uranyl ions and inhibition could be reversed (Fuhrmann et al., 1992). In the assays with uranyl ions as well as with other competitive inhibitors, these were initially mixed with the labelled sugar in the buffer and incorporation was started by the addition of cells. Filters were placed in scintillation liquid (OptiPhase HiSafe II; LKB), and radioactivity was measured in a Beckman LS 6000LL scintillation counter. For concentrations of sugar above $0.1 \mathrm{M}$, the experimental values were not reproducible since blanks were too high. Experimental data were treated using the computer program MicroCal Origin (MicroCal Software).

Movements of $\mathbf{H}^{+}$associated with initial sugar uptake. $\mathrm{H}^{+}$ uptake was evaluated with a combined $\mathrm{pH}$ electrode in unbuffered cell suspensions as previously described by LoureiroDias (1988). If the addition of sugar solutions were to cause the uptake of $\mathrm{H}^{+}$, an alkalinization of the extracellular environment would be observed. All assays were performed at $26^{\circ} \mathrm{C}$.

Measurement of respiratory and fermentative fluxes. Consumption of $\mathrm{O}_{2}$ and production of $\mathrm{CO}_{2}$ were measured by conventional manometric techniques using a Warburg apparatus (Umbreit et al., 1964).

\section{RESULTS}

\section{Evaluation of the fructophilic behaviour in Z. bailii ISA 1307}

For evaluating whether, in the strain of $Z$. bailii involved in this study, the fructophilic behaviour described previously for other strains was present, growth parameters in batch aerobic cultures were calculated when the carbon sources were glucose $(1.6 \%, \mathrm{w} / \mathrm{v})$, fructose $(1 \cdot 6 \%, \mathrm{w} / \mathrm{v})$ or a mixture of both sugars $(0.5 \%$ each). The results are shown in Table 1. Growth was faster on fructose, and an

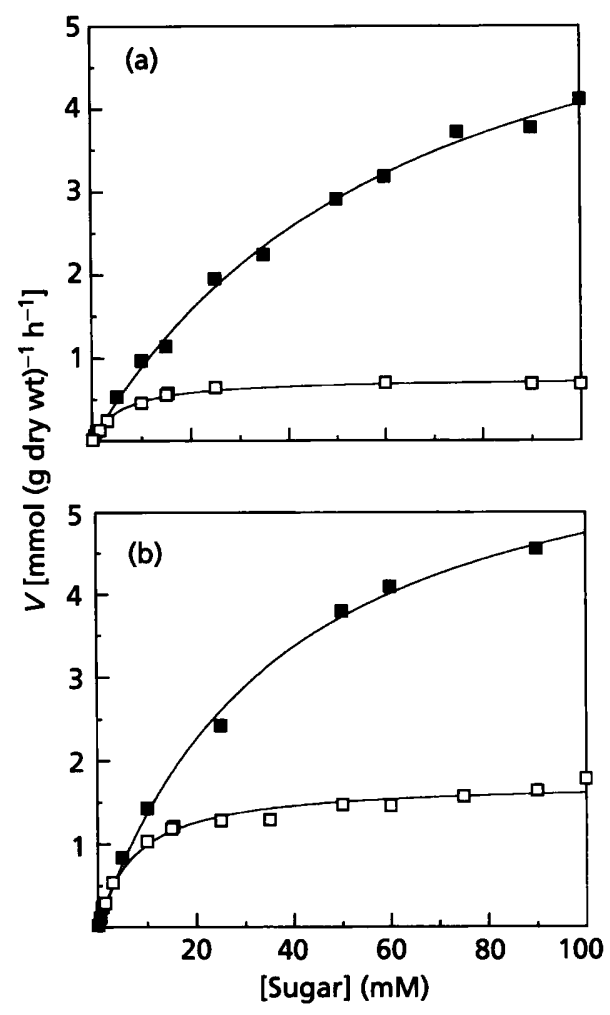

Fig. 1. Initial uptake of fructose $(\square)$ and glucose $(\square)$ measured in cells of $Z$. bailii grown on mineral medium with (a) $2 \%(w / v)$ fructose and (b) $2 \%(w / v)$ glucose.

Table 1. Growth parameters (specific growth rate, $\mu_{\max } ;$ yield coefficient, $Y$; specific substrate transfer rate, $q$ ) of $Z$. bailii ISA 1307 in batch cultures in mineral medium with different carbon sources

\begin{tabular}{|lccc|}
\hline Carbon source & $\boldsymbol{\mu}_{\text {max }}\left(\mathbf{h}^{-1}\right)$ & $\boldsymbol{Y}\left(\mathbf{g ~ g}^{-1}\right)$ & $\boldsymbol{q}\left(\mathbf{m m o l ~}^{-1} \mathbf{~ h}^{-1}\right)$ \\
\hline Glucose $\left(16 \mathrm{~g} \mathrm{l}^{-1}\right)$ & $0 \cdot 19$ & $0 \cdot 25$ & $4 \cdot 0$ \\
Fructose $\left(16 \mathrm{~g} \mathrm{l}^{-1}\right)$ & $0 \cdot 26$ & $0 \cdot 23$ & $6 \cdot 5$ \\
Glucose $\left(5 \mathrm{~g} \mathrm{l}^{-1}\right)+$ fructose $\left(5 \mathrm{~g} \mathrm{l}^{-1}\right)$ & $0 \cdot 23$ & $0 \cdot 28$ & - \\
\hline
\end{tabular}


Table 2. Kinetic parameters calculated from the initial uptake rates of fructose and glucose in cells of $Z$. bailii grown under different experimental conditions

\begin{tabular}{|c|c|c|c|}
\hline \multirow[t]{2}{*}{ Growth conditions } & \multirow[t]{2}{*}{ Transport } & \multicolumn{2}{|c|}{ Kinetic parameters } \\
\hline & & $K_{\mathrm{m}}(\mathrm{mM})$ & $V_{\max }\left(\mathrm{mmol} \mathrm{g}^{-1} \mathrm{~h}^{-1}\right)$ \\
\hline \multirow{2}{*}{ Glucose $(2 \%)$-grown cells } & Glucose & 7 & $1 \cdot 7$ \\
\hline & Fructose & $32 \cdot 9$ & $6 \cdot 3$ \\
\hline \multirow{2}{*}{ Glucose $(2 \%)$-grown cells $+4 \mathrm{~h}$ fructose $(10 \%)$} & Glucose & - & $0 \cdot 22$ \\
\hline & Fructose & $69 \cdot 7$ & $5 \cdot 8$ \\
\hline \multirow[t]{2}{*}{ Fructose $(2 \%)$-grown cells } & Glucose & 6 & $0 \cdot 75$ \\
\hline & Fructose & $65 \cdot 6$ & 6.7 \\
\hline \multirow[t]{2}{*}{ Fructose $(2 \%)$-grown cells $+4 \mathrm{~h}$ glucose $(10 \%)$} & Glucose & - & $0 \cdot 98$ \\
\hline & Fructose & $57 \cdot 8$ & $7 \cdot 6$ \\
\hline \multirow[t]{2}{*}{ Glycerol (2\%)-grown cells } & Glucose & - & $0 \cdot 2$ \\
\hline & Fructose & - & $1 \cdot 3$ \\
\hline Fructose $(10 \%)$-grown cells & Glucose & - & $0 \cdot 24$ \\
\hline
\end{tabular}

intermediate value was obtained when both sugars were present. The yield coefficients were similar on both sugars. The rate of fructose consumption was higher than for glucose, even in the mixed substrate growth (results not shown). In all cases, both sugars were consumed simultaneously and diauxic growth was not observed, in disagreement with that described for other strains (Emmerich \& Radler, 1983). We tried to reproduce the anaerobic conditions described by these authors, by bubbling $\mathrm{N}_{2}$ through the cultures, but under these conditions, Z. bailii ISA 1307 grew poorly, again consuming both sugars simultaneously.

\section{Kinetics of transport of fructose and glucose}

The methodology utilized to measure sugar transport in other yeasts was shown to be suitable for Z. bailii, although initial uptake was not linear for periods longer than 5 s. Fig. 1(a, b) depicts results obtained for the initial uptake of fructose and glucose in cells grown on each of these substrates in a typical experiment. Consistently, a higher $V_{\max }$ was found for the transport of fructose while a lower $K_{m}$ was found for glucose transport, as summarized in Table 2 . In particular, for higher concentrations, the ability to transport fructose was clearly higher than that for glucose.

\section{Assessing movements of $\mathrm{H}^{+}$associated with initial sugar uptake}

In many cases, when the mechanism of sugar transport in yeasts is a $\mathrm{H}^{+}$-symport, a transient alkalinization of an unbuffered cell suspension occurs during initial uptake of the substrate (Loureiro-Dias, 1988). In Z. bailii, no alkalinization was detected for either fructose or glucose under all the conditions tested. In particular, this test was performed in cells starved in medium without an energy source for $4 \mathrm{~h}$, since earlier literature indicated that $\mathrm{H}^{+}$-glucose symporters are usually repressible by glucose
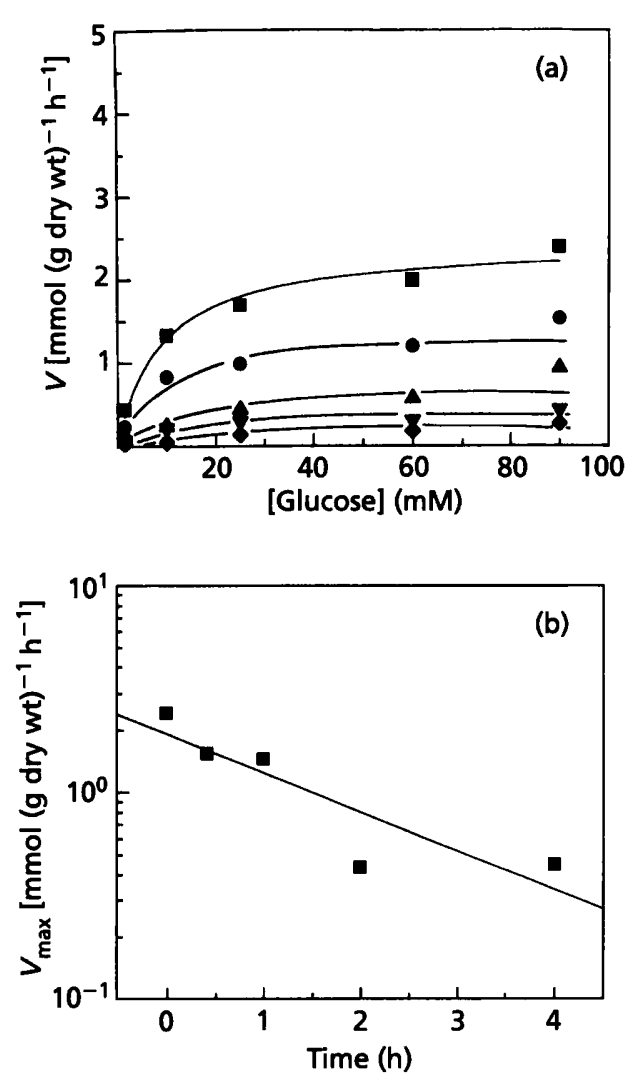

Fig. 2. Inactivation of glucose transport by addition of $10 \%$ $(w / v)$ fructose to cells of $Z$. bailii growing on $2 \%(w / v)$ glucose $\left(O D_{640}\right.$ of 0.8$)$. (a) Samples harvested at several times were tested for initial uptake of glucose $(\square, 0 \mathrm{~h} ; 0,0.4 \mathrm{~h} ; \Delta, 1 \mathrm{~h} ; \boldsymbol{\nabla}$, $2 \mathrm{~h} ; \bullet, 4 \mathrm{~h}$ ). (b) $V_{\max }$ calculated in (a) as a function of time.

(Loureiro-Dias, 1988). In these experiments, the addition of a sugar elicited external acidification after about $20 \mathrm{~s}$, probably as a consequence of the activity of the $\mathrm{H}^{+}$pumping plasma-membrane ATPase. 


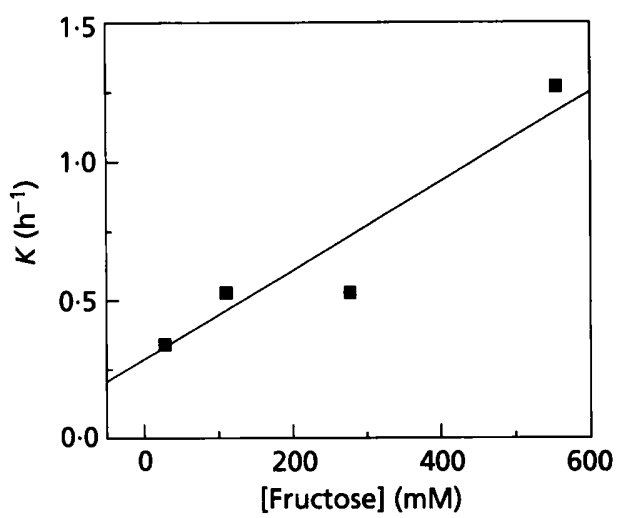

Fig. 3. Effect of fructose concentration on the exponential inactivation constant, $K$, of the glucose transport system of $Z$. bailii.

\section{Regulation of fructose and glucose transport systems}

In order to clarify the kinetics presented in Fig. 1, cells were grown under different conditions (see Table 2). When glycerol was the substrate for growth, the $V_{\max }$ values for fructose and glucose transport were, respectively, $1.3 \mathrm{mmol} \mathrm{g}^{-1} \mathrm{~h}^{-1}$ and $0.2 \mathrm{mmol} \mathrm{g}^{-1} \mathrm{~h}^{-1}$, suggesting that transport systems for both sugars were, at least partially, inductive.

Addition of $10 \%(\mathrm{w} / \mathrm{v})$ glucose to a culture growing on $2 \%(\mathrm{w} / \mathrm{v})$ fructose $\left(\mathrm{OD}_{640}\right.$ of 0.8$)$ resulted in an increase in the capacity of glucose transport, as observed after $4 \mathrm{~h}$. Addition of $10 \%(\mathrm{w} / \mathrm{v})$ fructose to a culture growing on $2 \%(\mathrm{w} / \mathrm{v})$ glucose $\left(\mathrm{OD}_{640}\right.$ of 0.8$)$ resulted in a loss of activity of the same transport. These results suggested that fructose might inactivate the glucose transporter. This hypothesis was checked in more detail by incubating glucose-grown cells with $10 \%$ fructose and monitoring the kinetics of glucose transport for $4 \mathrm{~h}$. Results are shown in Fig. 2(a). Fig. 2(b) shows the exponential decrease of the calculated $V_{\max }$ with time during this incubation. To further characterize the inactivation process, we studied the effect of fructose concentration on the exponential inactivation constant, $K$. As an estimate of $V_{\max }$, the uptake of $100 \mathrm{mM}$ glucose (a saturating concentration) was measured after incubation with fructose (in the range $0-600 \mathrm{mM}$ ) for periods up to $4 \mathrm{~h}$. In Fig. 3 , the dependence of $K$ on the external fructose concentration is represented. No saturation was found, even for concentrations of fructose one order of magnitude higher than the $K_{\mathrm{m}}$ of fructose transport.

\section{Search for competitive inhibitors of fructose and glucose transport}

The following compounds (at $60 \mathrm{mM}$ ) were tested as possible competitive inhibitors of the transport of fructose and glucose: 2-deoxy-D-glucose, D-ribulose, D-(-)-arabinose, D- $(+)$-xylose, 3-O-methyl-D-glucopyranose, L(-)-fucose, $\mathrm{D}-(+)$-glucosamine, $\mathrm{D}-(+)$-mannose, $\mathrm{L}-(-)$ sorbose, D-psicose and D-tagatose. D- $(+)$-Glucose and D-

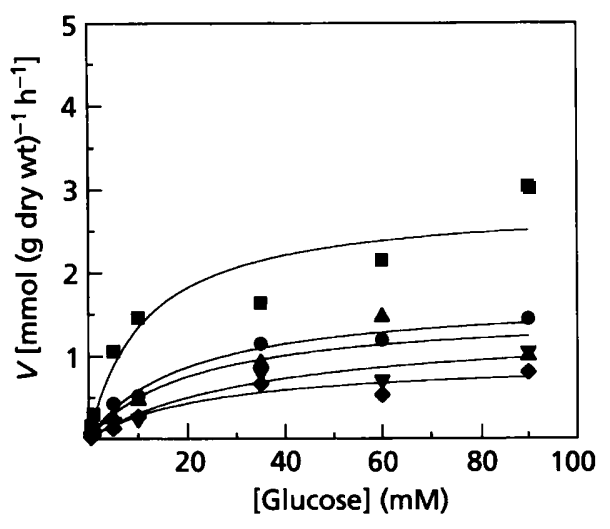

Fig. 4. Inhibition of the transport of glucose in cells of $Z$. bailii grown on $2 \%(w / v)$ glucose by uranyl nitrate in concentrations of $0(\square), 0.15(0), 0.25(\Delta), 0.35(\nabla)$ and $0.45(\diamond) \mathrm{mM}$.

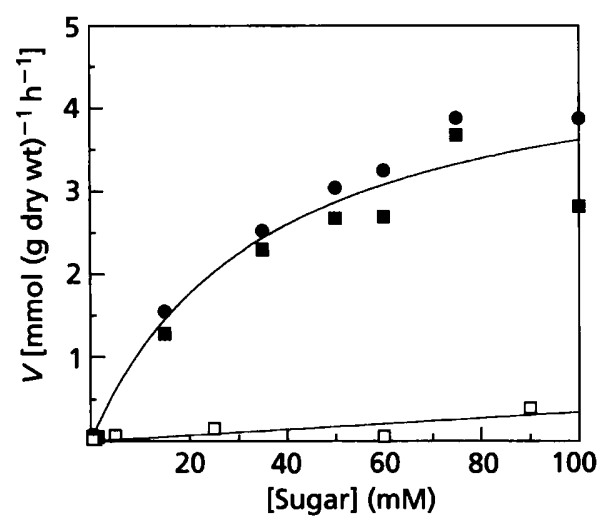

Fig. 5. Effect of uranyl nitrate $(1 \mathrm{mM})$ on the transport of fructose in cells of $Z$. bailii grown on $10 \%(w / v)$ fructose. $\square$, Glucose transport; $\square$, fructose transport in the absence and presence, respectively, of uranyl nitrate.

(-)-fructose were also tested as possible inhibitors of the fructose and glucose initial uptake, respectively. None of the compounds tested affected the transport of fructose, suggesting a high specificity of this transport system. Fructose and 2-deoxy-D-glucose competitively inhibited the transport of glucose, with $K_{\mathrm{i}}$ values of $12 \mathrm{mM}$ and $4 \mathrm{mM}$, respectively.

\section{Separation of the fructose and glucose transport systems by uranyl ions}

When the activity of the glucose transport system, in cells grown on $2 \%(\mathrm{w} / \mathrm{v})$ glucose, was tested in $80 \mathrm{mM}$ MES buffer, the presence of uranyl nitrate in concentrations up to $0.45 \mathrm{mM}$ caused inhibition, as shown in Fig. 4. Uranyl ions affected the glucose transport in a way described as mixed inhibition; $K_{\mathrm{m}}$ increased and $V_{\max }$ decreased. The $K_{\mathrm{m}}$ varied from 11 to $30 \mathrm{mM}$ and $V_{\max }$ from 2.8 to $0.94 \mathrm{mmol} \mathrm{h}^{-1} \mathrm{~g}^{-1}$ in, respectively, the absence and the presence of $0.45 \mathrm{mM}$ uranyl nitrate. It should be 
Table 3. Respiratory and fermentative fluxes of glucose or fructose $(5 \%, w / v)$, measured as $\mathrm{O}_{2}$ consumption and $\mathrm{CO}_{2}$ production, respectively, in cells grown under different experimental conditions

\begin{tabular}{|c|c|c|c|c|}
\hline Growth conditions & $\begin{array}{c}\text { Sugar } \\
\text { utilized }\end{array}$ & $\begin{array}{l}\text { Respiratory flux } \\
\left(\mathrm{mmol}^{-1} \mathrm{~g}^{-1}\right)\end{array}$ & $\begin{array}{l}\text { Fermentative flux } \\
\left(\mathrm{mmol} \mathrm{g}^{-1} \mathrm{~h}^{-1}\right)\end{array}$ & $\begin{array}{c}\text { Total flux } \\
\left(\mathrm{mmol}^{-1} \mathbf{h}^{-1}\right)\end{array}$ \\
\hline Glycerol $(0.5 \%)$ & Fructose & 0.56 & $0 \cdot 18$ & 0.74 \\
\hline Fructose $(2 \%)$ & Fructose & 0.62 & $2 \cdot 74$ & $3 \cdot 36$ \\
\hline \multirow[t]{2}{*}{ Glucose $(2 \%)$} & Fructose & 0.44 & $2 \cdot 33$ & $2 \cdot 78$ \\
\hline & Glucose & 0.52 & $1 \cdot 74$ & $2 \cdot 26$ \\
\hline \multirow[t]{2}{*}{ Glucose $(2 \%)+2 \mathrm{~h}$ fructose $(10 \%)$} & Fructose & 0.43 & $2 \cdot 10$ & $2 \cdot 53$ \\
\hline & Glucose & 0.49 & $0 \cdot 83$ & $1 \cdot 32$ \\
\hline \multirow{2}{*}{ Glucose $(2 \%)+4 \mathrm{~h}$ fructose $(10 \%)$} & Fructose & 0.36 & $1 \cdot 92$ & $2 \cdot 28$ \\
\hline & Glucose & 0.42 & $0 \cdot 45$ & 0.87 \\
\hline
\end{tabular}

emphasized that there was no previous incubation with uranyl nitrate, since substrate and inhibitor were added to the cells at time zero of the incorporation.

For assessing the effect on the fructose transport system, the cells were grown on $10 \%(\mathrm{w} / \mathrm{v})$ fructose, reducing the activity of the glucose transport system to very low levels (Fig. 5; Table 2). In this case, the transport of fructose was not affected by $1 \mathrm{mM}$ uranyl nitrate (Fig. 5). When the same experiment was performed with cells grown on $2 \%(\mathrm{w} / \mathrm{v})$ glucose (as in Fig. 1b), the activities of both transport systems were affected (results not shown), suggesting again that fructose is utilizing the glucose permease.

\section{Effects of the regulation of sugar transport on the metabolic flux}

Table 3 summarizes the results obtained for respiration and fermentation rates and total metabolic fluxes in cells grown under different conditions, when several substrates were supplied. When these results are compared with those of Table 2, the most prominent result is that the high velocity measured for fructose transport was not shown in the metabolic flux in vivo. This may be an indication that transport is not the main bottleneck in fructose catabolism by resting cells of $Z$. bailii. Data in Table 3 also substantiate the main features of regulation observed in transport experiments, namely, the partial inducibility of the transporters and the inactivation of the glucose transporter by fructose.

\section{DISCUSSION}

Summing up the results presented, we can claim that in $Z$. bailii there are two independent transporters: one for fructose and another for glucose plus fructose. Three mechanisms were identified which favour the transport of fructose over that of glucose, particularly at high concentrations: (i) the transport system specific for fructose showed a higher capacity; (ii) fructose at high concentrations significantly inactivated the glucose transporter, preventing the uptake of this sugar; (iii) fructose was able to utilize the glucose transporter, by competing with glucose.
We tried to characterize these transporters from an energetic point of view: the transient alkalinization of an unbuffered cell suspension during the initial uptake of the sugars might indicate a mechanism of $\mathrm{H}^{+}$-sugar symport. No alkalinization was observed. If a nonmetabolizable competitive inhibitor had been found, the ability of the transporter to actively accumulate the substrate would have been tested, but these experiments could not be carried out. In the future, we will try to prepare membrane vesicles of cells of $Z$. bailii grown under different conditions and use these vesicles as a cellular model devoid of metabolic activity.

Our results indicate that both systems are partially inducible. Glucose induced fructose transport, although it was not a substrate. In this case, perhaps we are not dealing with a specific induction but rather with a general expansion of cell activity.

It is interesting to note that the presence of glucose in the growth medium increased the activity of the fructose transport as compared with fructose-grown cells. This behaviour is in agreement with the other observations: in glucose-grown cells both systems are present and can be utilized by fructose.

The experiments with uranyl ions constitute a piece of evidence that in $Z$. bailii two distinct transport systems preferentially transport either fructose or glucose: the uptake of glucose was strongly inhibited, while the transport of fructose was not inhibited at all in cells in which glucose was not taken up. The pattern of glucose inhibition by uranyl ions is similar to that described by Fuhrmann et al. (1992) for S. cerevisiae. In both cases, the results suggest that the inhibition had a component of competitive nature, although higher concentrations of uranyl ions were used in $Z$. bailii. The results support the hypothesis that a dimeric complex of uranyl ions might act as a substitute for glucose at the binding site of the permease (Fuhrmann et al., 1992). In our case, similar results were obtained by either preincubating the cells or adding the inhibitor together with the substrate to start incorporation of the label. This indicated an instantaneous specific effect which did not affect the permease specific for fructose. 
As a whole, the results reported here represent a confirmation of the model proposed for the fructophilic behaviour in Z. bailii, earlier proposed by Emmerich \& Radler (1983). However, the measurement of catabolic fluxes in resting cells does not support this model completely, indicating that, besides transport, additional regulatory mechanisms are controlling the flux.

The rate of fructose inactivation of the glucose transporter increased with fructose concentration, as was first described for the inactivation by glucose of the $\mathrm{H}^{+}$-glucose symporter in Candida wickerhamii (Spencer-Martins \& van Uden, 1985). A different pattern was found for the inactivation by glucose of the maltose transporter in Candida utilis: in this case saturation kinetics were found with a $K_{\mathrm{m}}$ of the same order of magnitude as the $K_{\mathrm{m}}$ for glucose transport (Peinado et al., 1987). In the case of $C$. utilis, the mechanism of inactivation probably involves the uptake of glucose prior to it being able to act as an inactivator. In the cases of $C$. wickerbamii and $Z$. bailii, we are probably dealing with a situation in which the inactivator is recognized outside the cells by low-affinity sensors. In contrast, in Z. bailii, inactivation of the glucose transporter was not total under all conditions tested. However, in all experiments it became clear that while poor inactivation occurred for low concentrations of fructose, this became very significant as the concentration increased. The poor effect of low concentrations of fructose on glucose transport regulation may be responsible for the fact that no diauxic growth was observed in mixtures of the two sugars, since the glucose uptake may occur before the total exhaustion of fructose.

Our results introduce a new pattern of glucose and fructose uptake regulation in yeasts. Transport systems with a $K_{\mathrm{m}}$ in the range $30-70 \mathrm{mM}$ have previously been shown to be either an artifact (Benito \& Lagunas, 1992) or a complex situation involving several gene products as in the case of the transport of glucose in $S$. cerevisiae (Reifenberger et al., 1995). In Z. bailii, we found a kinetically simple, uranyl-insensitive, highly specific transporter for fructose. This transport system may be an important tool that enables this yeast to dominate environments like high-fructose syrups where $Z$. bailii is responsible for severe spoilage. Usually, in other yeasts, the glucose concentration acts as the key regulator of other transport processes, being a strong inhibitor of fructose uptake and utilization. In $Z$. bailii, the existence of two separate transport systems, the glucose system with higher affinity and lower capacity than the fructose system, seems to be related to the fact that this yeast is a strong infective agent of food substrates rich in fructose.

\section{ACKNOWLEDGEMENTS}

This work was supported by the EC (contract PL 93-830).

\section{REFERENCES}

Benito, B. \& Lagunas, R. (1992). The low-affinity component of Saccharomyces cerevisiae maltose transport is an artifact. J Bacteriol 174, 3065-3069.

Bourquelot, E. (1886). Recherches sur la fermentation alcoolique d'un mélange de deux sucres. Ann Chim Phys 9, 245-275.

Cirillo, V.P. (1968). Relationship between sugar structure and competition for the sugar transport system in baker's yeast. $J$ Bacteriol 95, 603-611.

Emmerich, W. \& Radler, F. (1983). The anaerobic metabolism of glucose and fructose by Saccharomyces bailii. J Gen Microbiol 129, 3311-3318.

Fuhrmann, G. F., Storch, D., Bode, H.-P. \& Völker, B. (1992). Inhibition of glucose transport in Saccharomyces cerevisiae by uranyl ions. $J$ Biotechnol 27, 75-84.

Heredia, C. F., Sols, A. \& DelaFuente, G. (1968). Specificity of the glucose transport in yeast. Eur J Biochem 5, 321-329.

Kotyk, A. (1967). Properties of the sugar carrier in baker's yeast. Folia Microbiol 12, 121-131.

Loureiro-Dias, M. C. (1988). Movements of protons coupled to glucose transport in yeasts. A comparative study among 248 yeast strains. Antonie Leeunenboek 54, 331-343.

Neves, L., Pampulha, M. E., Loureiro, V. \& Loureiro-Dias, M. C. (1994). Resistance of food spoilage yeasts to sorbic acid. Lett Appl Microbiol 19, 8-11.

Peinado, J. M., Barbero, A. \& van Uden, N. (1987). Repression and inactivation by glucose of the maltose transport system of Candida utilis. Appl Microbiol Biotechnol 26, 154-157.

Reifenberger, E., Freidel, K. \& Ciriacy, M. (1995). Identification of novel HXT genes in Saccharomyces cerevisiae reveals the impact of individual hexose transporters on glycolytic flux. Mol Microbiol 16, 157-167.

Rodrigues de Sousa, H., Spencer-Martins, I. \& van Uden, N. (1990). Active fructose transport in Saccharomyces sensu stricto. Taxonomic implications. Acta Varia 5, 127-134.

Sols, A. (1956). Selective fermentation and phosphorylation of sugars by Sauternes yeast. Biochim Biophys Acta 20, 62-68.

Spencer-Martins, I. \& van Uden, N. (1985). Inactivation of active glucose transport in Candida wickerbamii is triggered by exocellular glucose. FEMS Microbiol Lett 28, 277-279.

van Uden, N. (1967). Transport-limited fermentation and growth of Saccharomyces cerevisiae and its competitive inhibition. Arch Microbiol 58, 155-168.

Umbreit, W. W., Burris, R. H. \& Stauffer, J. F. (1964). Manometric Techniques, 4th edn. Minneapolis: Burgess Publishing.

Walsh, M. C., Smits, H. P., Scholte, M. \& Van Dam, K. (1994). Affinity of glucose transport in Saccharomyces cerevisiae is modulated during growth on glucose. J Bacteriol 176, 953-958.

Received 17 November 1995; revised 29 January 1996; accepted 31 January 1996. 